\title{
CORRESPONDENCE
}

\section{Human Papillomavirus and Cervical Cancer - Current Status of Vaccination Against Human Pathogenic Papillomavirus}

by PD Dr. med. Martin Löning, Prof. Dr. rer. nat. Lutz Gissmann, Prof. Dr. med. Klaus Diedrich, Prof. Dr. med. Klaus Friese,

Prof. Dr. med. Rolf Kreienberg, Prof. Dr. med. Peter Hillemanns, in volume 41/2007
3. Sawaya GF, SMith-McCune K: HPV vaccination - more answers, more questions. N Engl J Med 2007; 19: 1997-3.

Dr. med. Martin Hirte

Dr. med. Steffen Rabe

Dr. med. Stefan Schmidt-Troschke

"Ärzte für individuelle Impfentscheidung e.V."

Gerhard-Kienle-Weg 4

58313 Herdecke, Germany

Conflict of interest statemen

The authors declare that no conflict of interest exists according to the

guidelines of the International Committee of Medical Journal Editors.

\section{Low Efficacy}

The FUTURE II study (1) shows a significantly lower efficacy for HPV vaccination than the authors imply in their euphoric article: its efficacy across all cervical lesions is just $17 \%$. In high grade cervical dysplasia, the best surrogate parameter for cervical carcinoma, no statistically significant effect at all is demonstrable for HPV vaccination (2).

A leading article in the New England Journal of Medicine (3) therefore describes the effect of HPV vaccination as modest; it is expected to be useful to the health services only in the most favourable of circumstances. The efficacy of side-effect free cervical screening on the other hand is $90 \%$. In conclusion: vaccinated individuals still need screening, but screened individuals do not need vaccination.

In addition to the inadequately established efficacy, caution should have been indicated in STIKO (the German Standing Committee on Vaccination) on account of other unresolved problems such as serotype replacement, side effects, the unclear duration of action, and possible negative effects on motivation for screening.

The HPV vaccination guidelines must not least be viewed critically due to the massive lobbying on the part of the manufacturers: in Germany as elsewhere, decision makers have been supported by both manufacturers in the run up to the recommendation for vaccination, and the fact that one of the authors profits directly from the sale of the medications promoted in his article also raises questions.

Before a vaccination program is introduced whose exorbitant cost could increase statutory health insurance contributions by up to $0.1 \%$, its costs, efficacy, and safety should be compared with those of other preventive strategies in a Health Technology Assessment, e.g., with strategies such as anti smoking campaigns or education programs aimed at promoting a healthy lifestyle or preventing cancer.

DOI: 10.3238/arztebl.2008.0022a

\section{REFERENCES}

1. FUTURE II Study Group: Quadrivalent vaccine against human papilIomavirus to prevent high-grade cervical lesions. N Engl J Med 2007, 356: 1915-27.

2. Arznei-Telegramm: HPV-Impfstoff Gardasil: Nutzen zu hoch eingeschätzt? AT 2007; 38: 57-9.

\section{Reduction in Cervical Cancers Proven?}

The authors of this review article describe among other things the results of phase III studies of the tetravalent HPV vaccine gardasil. They conclude: "Overall, these results show that a reduction in anogenital diseases including cervical cancers is already observed in all the vaccinated women in the first three years after the vaccination." Given that no cervical carcinomas were observed neither in the placebo nor the vaccinated group, I would welcome clarification as to the evidence base for the claim for a reduction in cervical cancers.

DOI: 10.3238/arztebl.2008.0022b

\section{Stefanie Schenk}

Ärztin

Redaktion arzneitelegramm

A.T.I. Arzneimittelinformation Berlin $\mathrm{GmbH}$

Bergstr. 38A

Wasserturm

12169 Berlin, Germany

redaktion@arznei-telegramm.de

\section{Conflict of interest statement}

The authors declare that no conflict of interest exists according to the guidelines of the International Committee of Medical Journal Editors.

\section{Efficacy Unproven}

The wealth of numbers presented obscures the fact that HPV DNA is demonstrable in only a minority of women infected with HPV, one to two years after infection. According to international studies, around $70 \%$ of women acquire HPV infection over a lifetime. Seroprevalence data on HPV infection and HPV DNA for Germany are lacking (1); an unquantifiable but small minority of girls and women in Germany suffers from persistent HPV infection, which does not necessarily lead to cervical carcinoma.

A systematic review finds no evidence that the incidence or mortality from cervical carcinoma are reduced by HPV vaccines (2). NNTs for the estimation of efficacy of the vaccine show the following: were vaccine protection to be lifelong, 324 girls would need to be vaccinated to prevent one carcinoma. If vaccine protection lasted 30 years, the number would rise to 9080 (3). These are hypothetical numbers, in the face of unknown 
duration of efficacy. The first author, who works for the manufacturer of gardasil, cannot be accused of presenting unfavourable results.

The efficacy of the vaccine is currently unknown, and may be extremely modest or absent. HPV vaccination certainly cannot replace screening, albeit this is in need of improvement. Could not available resources be spent better in a society which prioritizes prevention than to confront minors with measures and advice whose effects are as yet unpredictable? Young men, meanwhile, are spared from any confrontation with sexually transmitted diseases: we now have a vaccination for the female sex. Medicalization strategies remain fashionable, apparently, even for minors. What will be the next "innovation"?

DOI: $10.3238 /$ arztebl.2008.0022c

\section{REFERENCES}

1. Mitteilung der Ständigen Impfkommission (STIKO) am Robert-KochInstitut. Impfung gegen humane Papillomaviren (HPV) für Mädchen von 12 bis 17 Jahren - Empfehlung und Begründung. Epidemiologisches Bulletin 23. März 2007/Nr. 12.

2. Rambout L, Hopkins L, Hutton B, Ferguson D: Prophylactic vaccination against human papillomavirus infection and disease in women: a systematic review of randomized controlled trials. CMAJ 2007; 177: 469-79

3. Brisson M, van de Velde N, de Wals P, Boily M-C: Estimating the number needed to vaccinate to prevent diseases and death related to human papillomavirus infection. CMAJ 2007; 177: 464-8.

Prof. Dr. med. Martina Dören

Charité - Universitätsmedizin Berlin

Campus Benjamin Franklin

Professur Frauenforschung und 0steologie

12200 Berlin, Germany

Martina.Doeren@charite.de

\section{Conflict of interest statement}

The author is a member of an advisory working group for the information portal "Women's health and health promotion," on behalf of the Federal Health Education Association (Bundeszentrale für gesundheitliche Aufklärung - BZgA).

\section{The Cost Debate}

The causal link between HPV infection and cervical carcinoma was established 15 years ago. A safe vaccine against the four highest risk viruses achieved in three IM doses over 6 months is undoubtedly a huge success.

HPV negative girls or young women enjoy $100 \%$ protection for 5 (possibly 10) years. In those already infected with HPV or with an associated cervical lesion, fewer than half benefit. The population of 12- to 17-year-old females in Germany is 2.5 million. The vaccine costs would initially amount to 1.25 billion euros (currently 500 euros per vaccine, excluding the costs associated with administration) for this group. To this must be added the cost of repeat vaccination after 5 years (possibly after 10 years). An additional 380000 girls who reach the age of 12 , are added to this population annually, at a vaccination cost of 200 million euros assuming the desired $100 \%$ uptake rate.

These must be set against 6500 new cervical carcinomas. Assuming a total population of 82 million Ger- mans with around half female, cervical carcinoma will affect 1 in 13000 . This risk is by no means equally distributed among women. Heavy smokers, for example, have a significantly higher risk. This is reflected in clinics where cytological abnormalities are discussed.

In conclusion: timely vaccination certainly protects against HPV infection and its associated anogenital lesions. Treatment costs must be set against vaccination costs, which are in the billions of euros. The incidence of breast cancer is seven times that of cervical carcinoma. Health economists must clarify the respective contributions of screening and vaccination for these diseases to rationing of health care resources. This would lead to a discussion of individual participation in cost, as against increasing statutory health insurance premiums. DOl: 10.3238/arztebl.2008.0023a

Prof. Dr. med. J. Matthias Wenderlein

Universitätsfrauenklinik Ulm

Prittwitzstr. 41

89075 Ulm, Germany

wenderlein@gmx.de

\section{Conflict of interest statement}

The authors declare that no conflict of interest exists according to the guidelines of the International Committee of Medical Journal Editors.

\section{In Reply:}

It is unsurprising given the topicality of the subject of HPV vaccination that it elicited both numerous positive responses and some which were critical. Hirte et al., for example, from the organization "Doctors for Individualized Vaccination Decisions" ("Ärzte für individuelle Impfentscheidung e. V.") - who also adopt a highly critical stance in relation to measles vaccination - assume a significantly lower efficacy of HPV vaccination, which is around $17 \%$, taking into account the prevalence of CIN 2-3 in the total population, i.e., including women with primary HPV infection. This is, in itself, correctly quoted from our article. No invasive cervical carcinomas were detected at three-year follow-up, as Schenk observed. The development of cervical carcinoma takes at least 10 years, however, sometimes decades. At three-year follow-up, however, a large number of high grade dysplasias (CIN 2-3) had developed against a background of prevalent HPV infection at the inception of the study.

It was demonstrated both in the FUTURE studies and in the recently published ramdomized phase III study of Hildesheim et al. that young women with HPV infection or dysplasia do not benefit from vaccination. The HPV 16/18 vaccination does not improve virus elimination and should therefore not be used in the presence of existing infection $(1,2)$. It can, however, for example, prevent HPV 18 infection in women who are only HPV 16 positive. In addition, it should be noted that the vaccination effect will become increasingly noticeable over the years, as the placebo group become infected with HPV.

The best time for vaccination for girls and young women is before first sexual contact or before first 
HPV infection. More than two thirds of all women will become infected with HPV at least once during their lifetime. Men are also affected, in particular via genital warts. Efficacy is to be expected due to good immune response, but is not yet clinically proven.

The large studies to date showed such benefit in 15- to 25-year-old women not infected with HPV 16/18 that preventive vaccination was introduced in most industrialized nations worldwide (3).

As Dören and Wenderlein observe, however, the costs are high and may jeopardize the funding of other services - in particular where economic evaluations are lacking. These concerns are understandable given the costs. Nonetheless, the first cost effectiveness analyses carried out in a German context supported the vaccine's implementation (5). The number needed to vaccinate is around 120 in Germany, to prevent a single case of cervical carcinoma. The number is 6 for the tetravalent vaccine to prevent one case of disease due to HPV $6,11,16$, or 18 . The duration of protection is significant, in this regard.

The PAP smear based screening program introduced in Germany in the 1970s contributed to a significant reduction in invasive carcinomas. Regrettably, only around half of eligible women take up screening today in Germany, so that Germany has the highest incidence of cervical carcinoma in Western Europe, with 12 cases per 100000 population per year, a figure which has remained constant since the mid 1980s (4). Unfortunately, an organized screening programme with a recall system has not been introduced. This would undoubtedly have a marked effect on the inci- dence of cervical carcinoma. This makes it all the more important to introduce HPV vaccination, as a promising and reliable intervention, on a nationwide basis.

DOI: 10.3238/arztebl.2008.0023b

\section{REFERENCES}

1. Koutsky LA et al.: Quadrivalent vaccine against human papillomavirus to prevent high-grade cervical lesions. N Engl J Med 2007; 356: 1915-27.

2. Hildesheim A, Herrero R, Wacholder S et al.: Effect of human papilIomavirus 16/18 L1 viruslike particle vaccine among young women with preexisting infection: a randomized trial. JAMA 2007; 298: 743-53.

3. Rambout L, Hopkins L, Hutton B, Fergusson D: Prophylactic vaccination against human papillomavirus infection and disease in women: a systematic review of randomized controlled trials. CMAJ 2007; 177: 469-79.

4. Altenhofen L: Hochrechnung der Akzeptans von Gesundheitsuntersuchungen und Krebsfrüherkennungsuntersuchungen bei gesetzlich Versicherten. Berlin: Zentralinstitut für die kassenärztliche Versorgung in der Bundesrepublik Deutschland 2005.

5. Petry KU, Breugelmans JG, Bénard S, Lamure E, Littlewood KJ, Hillemanns P: Cost of screening and treatment of cervical dyskaryosis in Germany. Europ J Gynaecol Oncol 2007; in press.

PD Dr. med. Martin Löning

Prof. Dr. med. Peter Hillemanns

Medizinische Hochschule Hannover

Klinik für Frauenheilkunde u. Geburtshilfe

Carl-Neuberg-Str. 1

30625 Hannover, Germany

E-Mail: loening.martin@mh-hannover.de

Conflict of interest statement

The authors have received fees for speaking and consultancy, and travel

expenses, from several firms who are active in the field of cytology/molecular diagnostics/vaccines. 